\title{
Fast atmosphere-ocean model runs with large changes in $\mathrm{CO}_{2}$
}

\author{
Gary L. Russell, ${ }^{1}$ Andrew A. Lacis, ${ }^{1}$ David H. Rind, ${ }^{1}$ Christopher Colose, ${ }^{2}$ \\ and Roger F. Opstbaum ${ }^{3}$ \\ Received 24 September 2013; revised 22 October 2013; accepted 22 October 2013; published 12 November 2013.
}

[1] How does climate sensitivity vary with the magnitude of climate forcing? This question was investigated with the use of a modified coupled atmosphere-ocean model, whose stability was improved so that the model would accommodate large radiative forcings yet be fast enough to reach rapid equilibrium. Experiments were performed in which atmospheric $\mathrm{CO}_{2}$ was multiplied by powers of 2 , from $1 / 64$ to 256 times the 1950 value. From 8 to 32 times, the $1950 \mathrm{CO}_{2}$, climate sensitivity for doubling $\mathrm{CO}_{2}$ reaches $8^{\circ} \mathrm{C}$ due to increases in water vapor absorption and cloud top height and to reductions in low level cloud cover. As $\mathrm{CO}_{2}$ amount increases further, sensitivity drops as cloud cover and planetary albedo stabilize. No water vapor-induced runaway greenhouse caused by increased $\mathrm{CO}_{2}$ was found for the range of $\mathrm{CO}_{2}$ examined. With $\mathrm{CO}_{2}$ at or below $1 / 8$ of the 1950 value, runaway sea ice does occur as the planet cascades to a snowball Earth climate with fully ice covered oceans and global mean surface temperatures near $-30^{\circ}$ C. Citation: Russell, G. L., A. A. Lacis, D. H. Rind, C. Colose, and R. F. Opstbaum (2013), Fast atmosphere-ocean model runs with large changes in $\mathrm{CO}_{2}$, Geophys. Res. Lett., 40, 5787-5792, doi:10.1002/2013GL056755.

\section{Introduction}

[2] Global equilibrium climate sensitivity (ECS) is the change in surface temperature for doubling of $\mathrm{CO}_{2}$ when the climate system reaches energy balance equilibrium. Current climate models show that ECS ranges from about 2 to $4.5^{\circ} \mathrm{C}$ from current conditions. This paper discusses ECS changes for $\mathrm{CO}_{2}$, ranging from 1/64 to 256 times the 1950 mean concentration of $312 \mathrm{ppm}$. Prior work was done on a more modest range such as that of Hansen et al. [2005], which showed a monotonic increase of ECS as $\mathrm{CO}_{2}$ increased from $1 / 8$ to 8 . In a colder solar experiment, as their model approached a snowball Earth, ECS would increase significantly. Colman and McAvaney [2009], using a climate model with only a mixed layer ocean, showed decreasing ECS as $\mathrm{CO}_{2}$ increased from $1 / 16$ to 32 ; the ice/snow albedo feedback decreased as expected, but cloud feedback did not increase, contrary to Hansen's earlier results. Jonko et al. [2012], using NCAR climate models with $\mathrm{CO}_{2}$ multiplicative factors ranging from 1 to 8, produced results similar to Hansen et al. [2005].

\footnotetext{
${ }^{1}$ NASA Goddard Institute for Space Studies, New York, New York, USA.

${ }^{2}$ State University of New York at Albany, Albany, New York, USA.

${ }^{3}$ Bergen Community College, Paramus, New Jersey, USA.

Corresponding author: G. L. Russell, NASA Goddard Institute for Space Studies, 2880 Broadway, New York, NY 10025, USA.

(Gary.L.Russell@nasa.gov)

(C)2013. American Geophysical Union. All Rights Reserved. 0094-8276/13/10.1002/2013GL056755
}

[3] The climate model that is used here is a version of the Goddard Institute for Space Studies AtmosphereOcean Model (GISS-AOM) [Russell et al., 1995], which was used to contribute results to the Intergovernmental Panel on Climate Change (IPCC) AR4 SYR [2007]. The current model is simpler than the full GISS ModelE version that Hansen et al. [2005] used. The GISS-AOM was modified to be stable under a broad range of radiative forcings without adversely impacting its operational behavior or performance statistics.

\section{Fast Atmosphere-Ocean Model (FAOM)}

[4] GISS-AOM's novel features include its atmospheric step-mountain technology [Russell, 2007], a drag caused by unresolved mountains and sea mounts and realistic ocean tides. Its significant weaknesses include a coarse resolution, atmospheric condensates that are not carried over from one time step to the next, erratic C-grid ocean velocities, lakes and land ice with fixed surface areas, and externally specified input climatologies for radiative gas and aerosol variability.

[5] The radiative optical depth of clouds is proportional to the square root of condensate and to global constants for water and ice, for moist convection (0.06, and 0.025) and large-scale condensation ( 1 and 0.1 ). The total cloud cover diagnostic in Table 1 shows the fraction of time that the vertically integrated cloud optical depth exceeds 0.625 . When a total cloud exists, the cloud optical depth is summed from the top until it reaches 0.625 , which determines the cloud top pressure. If that pressure is less than $440 \mathrm{mb}$, the cloud is called high; if the pressure is greater than $680 \mathrm{mb}$, the cloud is called low. The model description of clouds and other parameters is available at http://aom.giss.nasa.gov/CONDENSE.html.

[6] The fast atmosphere-ocean model (FAOM) operates with $4^{\circ} \times 3^{\circ}$ resolution, land ice replaced by tundra, and a $100 \mathrm{~m}$ ocean using up to five layers. This allows the model to reach equilibrium much more rapidly, although it does decrease the ocean's heat transport, causing greater ice cover at northern latitudes. Basically, a reduction in the ocean circulation as the planet warms enables greater sea ice growth. This negative feedback that operates in the full ocean model is substantially reduced in the FAOM, thus causing FAOM's composite feedback to be larger. These two effects tend to increase ECS.

[7] A control simulation of FAOM was integrated from 1900 to 2100 using the atmospheric gases and aerosols for the year 1950 A.D. From the middle of this control simulation, the experiment simulations were initiated by slowly adjusting the control run $\mathrm{CO}_{2}$ mass so as to reach integer powers of 2 (over the range from $1 / 64 \times \mathrm{CO}_{2}$ to $256 \times \mathrm{CO}_{2}$ ) during the first year. The experiments were continued until the year 2100. In each experiment, water vapor adds to atmospheric mass, and $\mathrm{CO}_{2}$ adds to dry atmospheric mass, which 


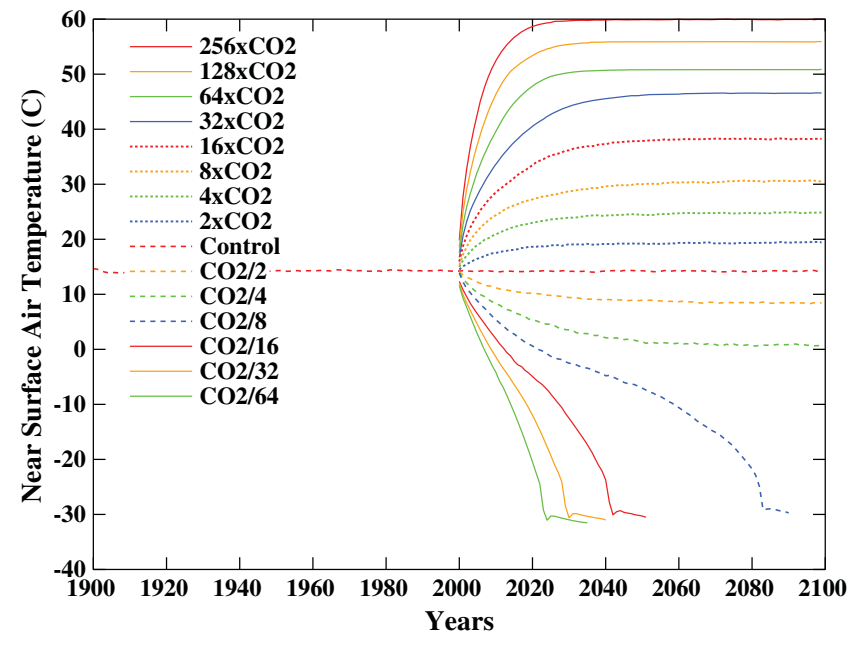

Figure 1. Global mean surface air temperature $\left({ }^{\circ} \mathrm{C}\right)$ versus time for each $\mathrm{CO}_{2}$ forcing run. Control run is the starting point for all experiments.

involves modifying the dry gas constant and dry specific heat capacity. At $256 \times \mathrm{CO}_{2}, 11 \%$ of the dry atmospheric mass is $\mathrm{CO}_{2}$. Otherwise, the model code, aerosols, ozone, and other trace gases are identical for each experiment run. In radiative modeling, the correlated $k$-distribution approach, for both shortwave (SW) and longwave (LW) radiation, implicitly retains the spectral dependence of the absorbing gases, thus making the radiative transfer calculations valid over large ranges of absorber amounts [Lacis and Oinas, 1991].

\section{Results of $\mathrm{CO}_{2}$ Experiments}

[8] Figure 1 shows global surface air temperature $T_{S}$ as a function of year for each $\mathrm{CO}_{2}$ experiment; the final $T_{S}$ covers a range of $90^{\circ} \mathrm{C}$. Using an idealized planet with similarities to FAOM, Hansen et al. [1984] showed that the time to reach equilibrium is proportional to the total feedback factor. With stronger feedbacks, the equilibrium temperature change is greater, causing the experiments to reach equilibrium more slowly since the radiative driving force is not proportionately stronger. As a result, the time evolution curves in Figure 1 have a less steep asymptotic shape for the stronger feedback cases.

[9] Sea ice becomes progressively more important in current and colder climates, causing increasing ECS. In $1 / 8 \times \mathrm{CO}_{2}$, the rising cumulative "gain factor" [Hansen et al., 1984] exceeds unity when sea ice covers $32 \%$ of the ocean. The inflection point of $T_{S}$ versus years in Figure 1 occurs around the year 2040, beyond which point, the planet cascades into runaway sea ice. Eventually, a new equilibrium is reached with ice covering the oceans, and $T_{S}$ having become $44^{\circ} \mathrm{C}$ colder. In more extreme cold experiments, sea ice was in the process of freezing the entire ocean until the ice hit the bottom of an ocean cell, bringing the simulation to a halt. Those experiments are not included in Tables 1-3 nor in Figures 2-6. Once the planet has become fully ice covered, the sea ice albedo feedback no longer increases with further $\mathrm{CO}_{2}$ reduction. For $4 \times \mathrm{CO}_{2}$ and for warmer climate runs, the sea ice is virtually absent and no longer a feedback.

[10] Table 1 presents global numbers averaged for the ninth decade of the experiments, just before the $1 / 8 \times \mathrm{CO}_{2}$ experiment
Table 1. Global Key Numbers Averaged Over the Ninth Decade of $\mathrm{CO}_{2}$ Experiment Runs $\left(1 / 8 \times \mathrm{CO}_{2} 5 \text { Years }\right)^{\mathrm{a}}$

\begin{tabular}{lcccccccccc}
\hline $\mathrm{CO}_{2}$ & $T_{S}$ & Palb & Ccov & C Lo & $\mathrm{C} \mathrm{Hi}$ & $\mathrm{C} \tau$ & Ctop & Prec & WV & Sice \\
\hline $1 / 8$ & -29.8 & 54.0 & 62.2 & 57.4 & 0.1 & 33.3 & 845 & 0.6 & 0.9 & 99.3 \\
$1 / 4$ & 0.7 & 36.2 & 68.9 & 41.4 & 7.2 & 8.0 & 730 & 2.3 & 10.7 & 25.1 \\
$1 / 2$ & 8.3 & 33.1 & 68.0 & 38.6 & 15.3 & 9.4 & 703 & 2.8 & 17.1 & 14.7 \\
1 & 14.2 & 31.1 & 66.2 & 35.4 & 18.6 & 10.2 & 679 & 3.1 & 25.0 & 6.6 \\
2 & 19.4 & 29.7 & 64.4 & 33.9 & 20.0 & 10.7 & 660 & 3.4 & 35.5 & 1.5 \\
4 & 24.9 & 28.2 & 60.2 & 30.7 & 20.8 & 10.7 & 636 & 3.7 & 53.2 & 0.0 \\
8 & 30.5 & 27.1 & 56.2 & 28.0 & 21.4 & 10.3 & 612 & 4.2 & 81.0 & 0.0 \\
16 & 38.2 & 25.2 & 48.2 & 22.4 & 20.7 & 9.1 & 572 & 4.9 & 138.4 & 0.0 \\
32 & 46.5 & 23.4 & 38.9 & 16.4 & 19.0 & 6.8 & 513 & 5.5 & 235.0 & 0.0 \\
64 & 50.9 & 22.8 & 33.9 & 13.4 & 17.6 & 5.8 & 491 & 5.7 & 298.1 & 0.0 \\
128 & 55.9 & 22.5 & 30.1 & 11.4 & 16.4 & 4.8 & 479 & 6.0 & 393.2 & 0.0 \\
256 & 59.9 & 23.4 & 30.0 & 11.1 & 17.4 & 5.0 & 476 & 6.0 & 487.0 & 0.0 \\
\hline
\end{tabular}

${ }^{\mathrm{a}}$ The columns list: $\mathrm{CO}_{2}$ multiplier, surface temperature $T_{S}\left({ }^{\circ} \mathrm{C}\right)$, planetary albedo (\%), total cloud cover (\%), low cloud cover $(\%)$, high cloud cover $(\%)$, cloud column optical depth, cloud top pressure $(\mathrm{mb})$, precipitation $(\mathrm{mm} / \mathrm{d})$, water vapor $\left(\mathrm{kg} / \mathrm{m}^{2}\right)$, and sea ice cover $(\%)$.

stopped. ECS is $5.15^{\circ} \mathrm{C}$ for doubling $\mathrm{CO}_{2}$ from the control. This value is large because FAOM has more sea ice than the real world and a weaker ocean circulation. ECS rises to about $8^{\circ} \mathrm{C}$ between $8 \times \mathrm{CO}_{2}$ and $32 \times \mathrm{CO}_{2}$ as water vapor and a positive cloud feedback more than compensate for the loss of sea ice. Between $128 \times \mathrm{CO}_{2}$ and $256 \times \mathrm{CO}_{2}$, ECS drops back to $4^{\circ} \mathrm{C}$ because clouds have become a negative feedback. In the cold experiments, ECS is between 6 and $8^{\circ} \mathrm{C}$ before growing sea ice consumes the planet.

[11] Radiative equilibrium analysis [e.g., Hansen et al., 1984] was performed over the ninth decade of each experiment attributing specific causes of the greenhouse effect in Table 2 and for solar reflection in Table 3 . The radiative modeling attribution was performed as outlined in Lacis et al. [2010] using the FAOM radiation model. As has been pointed out by Aires and Rossow [2003], in nonlinear climate systems, not only feedbacks but also radiative forcings are state dependent, evolving gradually as the climate system changes. This explains why the radiative flux contributions to the greenhouse effect that are attributed to the minor greenhouse gases are seen to vary in Table 2, even though the atmospheric amounts of these gases remain fixed throughout for all experiments. The Rayleigh scattering flux contribution

Table 2. Analysis of Global Annual LW Radiative Fluxes $\left(\mathrm{W} / \mathrm{m}^{2}\right)$ at Equilibrium Based on the Ninth Decade of Each Experiment ${ }^{\mathrm{a}}$

\begin{tabular}{lccccccccc}
\hline $\mathrm{CO}_{2}$ & $\mathrm{CO}_{2}$ & $\mathrm{GHG}$ & $\mathrm{H}_{2} \mathrm{O}$ & $\mathrm{CLo}$ & $\mathrm{CMi}$ & $\mathrm{CHi}$ & $\mathrm{GE}$ & $\boldsymbol{\sigma} T_{S}^{4}$ & $\mathrm{LW}_{\mathrm{E}}$ \\
\hline $1 / 8$ & 9.3 & 0.8 & 17.3 & 10.4 & 4.4 & 0.1 & 42.3 & 203.4 & 161.1 \\
$1 / 4$ & 19.9 & 4.7 & 53.3 & 12.6 & 12.3 & 6.0 & 108.8 & 326.7 & 217.9 \\
$1 / 2$ & 24.4 & 6.3 & 70.1 & 10.7 & 10.4 & 12.3 & 134.1 & 362.8 & 228.7 \\
1 & 28.0 & 7.6 & 85.7 & 12.1 & 9.0 & 14.1 & 156.4 & 391.9 & 235.5 \\
2 & 31.6 & 8.8 & 101.9 & 14.1 & 7.9 & 15.2 & 179.5 & 419.8 & 240.3 \\
4 & 34.9 & 10.0 & 122.2 & 13.3 & 6.7 & 18.9 & 206.0 & 451.2 & 245.2 \\
8 & 37.7 & 11.1 & 148.2 & 12.6 & 5.3 & 21.7 & 236.5 & 486.0 & 249.5 \\
16 & 39.8 & 12.5 & 190.5 & 10.7 & 4.9 & 22.0 & 280.3 & 536.1 & 255.8 \\
32 & 41.0 & 13.6 & 240.6 & 8.2 & 3.6 & 26.4 & 333.4 & 595.5 & 262.1 \\
64 & 42.6 & 14.2 & 263.0 & 6.9 & 3.5 & 33.5 & 363.7 & 627.5 & 263.8 \\
128 & 44.5 & 14.8 & 293.6 & 7.8 & 3.8 & 38.7 & 403.1 & 668.0 & 264.9 \\
256 & 46.4 & 15.0 & 308.2 & 20.3 & 5.7 & 44.0 & 439.6 & 700.3 & 261.7
\end{tabular}

${ }^{\mathrm{a}}$ The first column is the $\mathrm{CO}_{2}$ multiplier, followed by attributed flux contributions to the greenhouse strength, from $\mathrm{CO}_{2}$, minor GHGs, water vapor, low, middle, and high clouds. The sum GE is the total greenhouse strength. $\mathrm{LW}_{S}$ is Planck radiation $\sigma T_{S}^{4}$ emitted by the ground surface. $L_{E}$ is the outgoing thermal flux emitted by the Earth to space. Note that $\mathrm{GE}=\mathrm{LW}_{S}-\mathrm{LW}_{\mathrm{E}}$. 
Table 3. Analysis of Global Annual SW Radiative Fluxes (W/m²) at Equilibrium Based on the Ninth Decade of Each Experiment ${ }^{\mathrm{a}}$

\begin{tabular}{lcccccccccc}
\hline $\mathrm{CO}_{2}$ & $\mathrm{H}_{2} \mathrm{O}$ & Other & Surf & $\mathrm{SW}_{a}$ & $\mathrm{CLO}$ & $\mathrm{CMi}$ & $\mathrm{CHi}$ & Rayl & Surf & $\mathrm{SW}_{r}$ \\
\hline $1 / 8$ & 14.7 & 34.6 & 111.7 & 161.1 & 39.1 & 2.2 & 0.0 & 11.3 & 127.9 & 180.4 \\
$1 / 4$ & 34.9 & 28.7 & 154.3 & 217.9 & 50.4 & 9.7 & 1.8 & 13.7 & 48.0 & 123.6 \\
$1 / 2$ & 40.0 & 27.4 & 161.3 & 228.7 & 51.3 & 8.4 & 4.2 & 14.3 & 34.5 & 112.8 \\
1 & 43.6 & 26.1 & 165.8 & 235.5 & 48.5 & 10.8 & 3.7 & 14.8 & 28.1 & 106.0 \\
2 & 46.3 & 25.4 & 168.6 & 240.3 & 51.1 & 10.4 & 4.0 & 15.3 & 20.3 & 101.2 \\
4 & 49.0 & 24.8 & 171.4 & 245.2 & 45.8 & 9.0 & 5.3 & 15.6 & 20.6 & 96.3 \\
8 & 51.1 & 24.0 & 174.4 & 249.5 & 43.1 & 6.9 & 5.2 & 16.0 & 20.9 & 92.0 \\
16 & 53.0 & 22.9 & 180.0 & 255.8 & 36.1 & 5.9 & 5.7 & 16.5 & 21.5 & 85.7 \\
32 & 53.8 & 22.1 & 186.2 & 262.1 & 28.7 & 5.1 & 6.3 & 17.2 & 22.1 & 79.4 \\
64 & 54.3 & 21.6 & 187.9 & 263.8 & 24.0 & 4.2 & 9.8 & 17.7 & 22.1 & 77.7 \\
128 & 53.7 & 21.1 & 190.0 & 264.9 & 21.4 & 1.9 & 10.6 & 18.4 & 22.3 & 76.6 \\
256 & 54.0 & 19.9 & 187.8 & 261.7 & 23.5 & 1.1 & 13.7 & 19.4 & 22.2 & 79.8 \\
\hline
\end{tabular}

${ }^{\mathrm{a}}$ First column is the $\mathrm{CO}_{2}$ multiplier, followed by solar radiation absorbed by water vapor, other atmospheric absorbers, and the ground surface. $\mathrm{SW}_{a}$ is total solar radiation absorbed by Earth. Note that $\mathrm{SW}_{a}$ is equal to $\mathrm{LW}_{E}$ in Table 2. Reflected radiation by Earth is contributed by low, middle, and high clouds, Rayleigh scattering, and by the ground surface. $\mathrm{SW}_{r}$ is the total reflected solar flux. $\mathrm{SW}_{a}+\mathrm{SW}_{r}=341.5 \mathrm{~W} / \mathrm{m}^{2}$ is the incident solar flux.

in Table 3 also changes because of changing competition between cloud, atmospheric, and surface albedo interactions.

[12] Table 1 shows that as $\mathrm{CO}_{2}$ increases, the surface temperature increases strongly, accompanied by a steady decrease in planetary albedo because of decreasing total (and low) cloud cover. High clouds are seen to increase, peaking at $8 \times \mathrm{CO}_{2}$, then also exhibiting a slow decline. Most notable is the strong increase in water vapor with increasing temperature, a direct result of the exponential temperature dependence of Clausius-Clapeyron equation, which doubles the water vapor holding capacity of air for every $10^{\circ} \mathrm{C}$ increase in temperature. This makes water vapor a strong positive feedback over the entire range of $\mathrm{CO}_{2}$ experiments, as is fully evident in Tables 2 and 3.

[13] In Table $2, \mathrm{CO}_{2}$ along with the minor greenhouse gases that are being kept fixed are the radiative forcings in these climate experiments. This is because $\mathrm{CO}_{2}$ and the minor greenhouse gases are noncondensing gases, meaning that once they are injected into the atmosphere, they will remain in the system indefinitely. Meanwhile, the atmospheric distribution of water vapor and clouds is determined according to the local temperature-dependent meteorological conditions. In Table 2, it is the feedback effects, particularly water vapor, that are responsible for the rapid increase in greenhouse strength as the climate warms in response to increasing $\mathrm{CO}_{2}$. Table 3 shows the corresponding changes in the SW flux components as the climate warms in response to $\mathrm{CO}_{2}$ increases.

[14] Over the oceans, relative humidity at the surface remains largely unchanged. Over the continents, relative humidity decreases with increasing $\mathrm{CO}_{2}$ because rain is evaporated more rapidly and vapor is carried away more efficiently by moist convection, making the continents drier. Relative humidity exhibits only small variations above the planetary boundary layer, but as shown in Figure 2 below, large increases occur above the historical tropopause as the climate warms.

[15] Given the profiles of relative humidity, Figure 3 shows that in going from colder toward warmer climates, low clouds tend to decrease while high clouds increase. Changes from low water clouds to high ice clouds and from large-scale condensation to moist convective clouds have the effect of reducing the cloud optical depth and planetary albedo. The increase in tropical high clouds adds preferentially to the greenhouse effect, while the reduction in low clouds decreases the planetary albedo. Both effects increase ECS. After $128 \times \mathrm{CO}_{2}$, cloud optical depth again starts to increase as does planetary albedo. But this negative feedback is too feeble to overcome the strong positive feedback of water vapor and increase in dry atmospheric mass. Global precipitation shows a slow increase despite the rapid increase in column water vapor and temperature. This aspect agrees with earlier studies that find global precipitation not to be moisture limited and not scaling with Clausius-Clapeyron but responding instead to constraints related to atmospheric and surface energetics [O'Gorman et al., 2012].

[16] The latitudinal temperature distribution for present Earth conditions is affected by two significant factors: (1) the poles receive less insolation than do the tropics and (2) the planetary albedo is much greater at the poles than it is in the tropics due primarily to snow and sea ice cover. Each factor causes the polar temperatures to be much cooler than those in the tropics in spite of the smoothing effect of dynamics (see Figures 4 and 5). As $\mathrm{CO}_{2}$ forcing increases, the surface albedo contribution to planetary albedo diminishes, stabilizing at about $10.3 \%$ beyond $8 \times \mathrm{CO}_{2}$. The cloud contribution of the latitudinal distribution of planetary albedo does not change much up until $16 \times \mathrm{CO}_{2}$. After that, cloud optical depth decreases at the poles and increases in the tropics. The net effect of this is that these warm experiments have much smaller gradient in planetary albedo.

[17] Downward radiation absorbed by the continents is returned to the atmosphere as dry heat. Over the oceans, it is returned as latent energy that does not immediately affect the air temperature. $T_{S}$ increases more rapidly over the continents than over the planet as a whole. As seen in going from control to $4 \times \mathrm{CO}_{2}, T_{S}$ increases by $13^{\circ} \mathrm{C}$ over the continents, but only $10.7^{\circ} \mathrm{C}$ globally. In the warmest experiment runs,

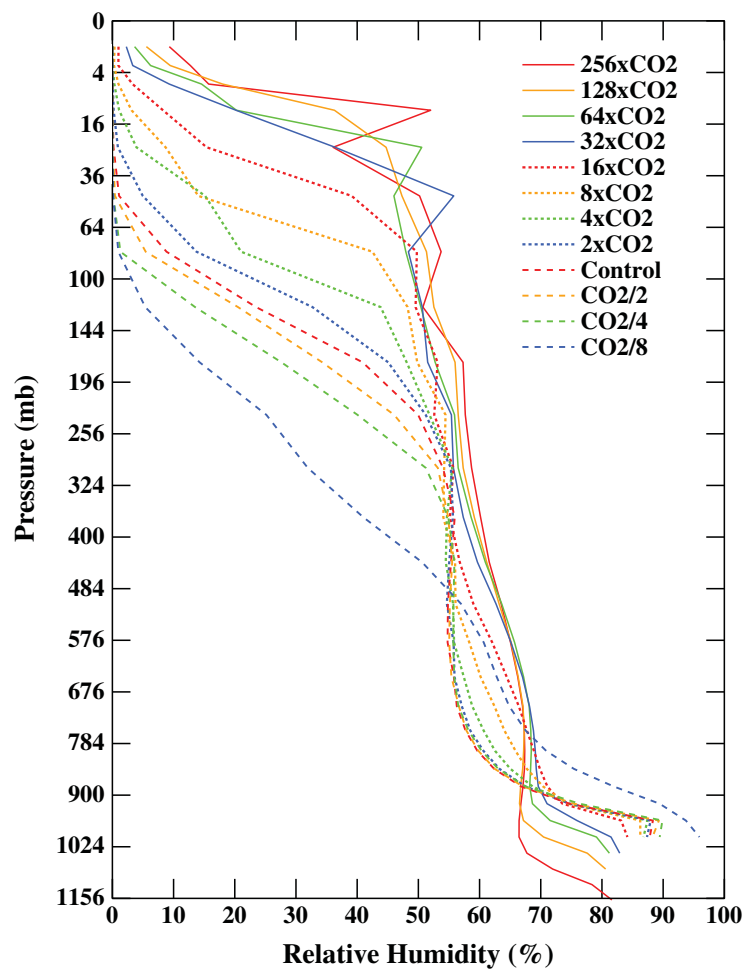

Figure 2. Vertical profiles of relative humidity computed for the ninth decade of run time as a function of pressure. 


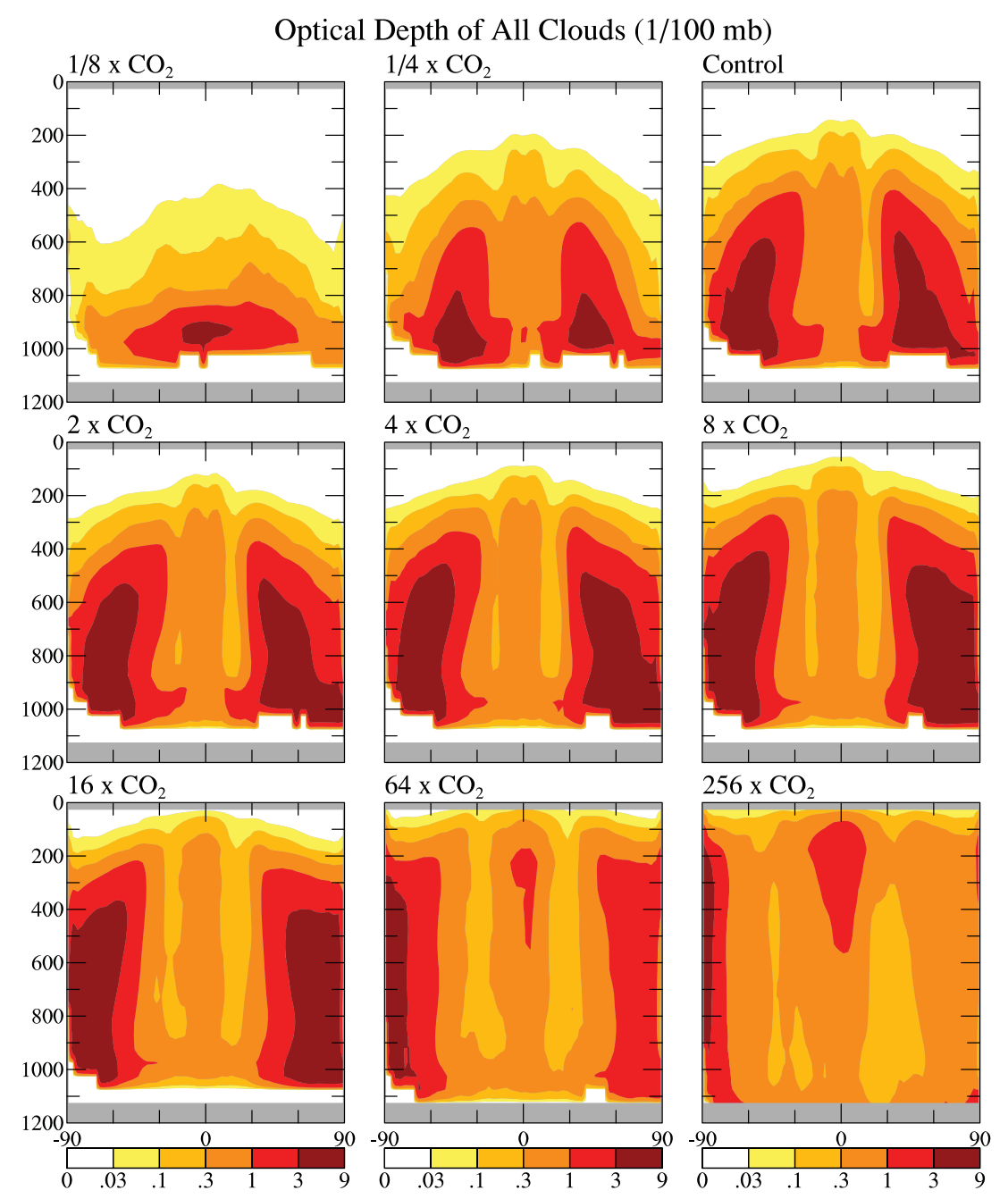

Figure 3. Cloud optical depth as a function of latitude and pressure for selected experiment runs averaged over the ninth decade of run time.

this continental effect on northern middle latitudes, and Antarctica to a lesser extent, is noticeable in Figure 4, now that the masking effect of planetary albedo has been reduced.

[18] In reduced $\mathrm{CO}_{2}$ experiments, the rapid expansion of sea ice to low latitudes results in tropical cooling. The latitudinal distribution of planetary albedo is muted and so is the temperature gradient. Unlike other experiments which reached equilibrium, the coldest $\mathrm{CO}_{2}$ experiments, $1 / 8,1 / 16,1 / 32$, and $1 / 64$, were still pumping heat out of the oceans and were increasing their sea ice thicknesses when they came to a stop because of sea ice hitting ocean bottom. Were these experiments to be integrated longer, the final latitudinal temperature distribution would be considerably flatter than that in the control.

[19] Except for the coldest of experiments, dynamical static energy convergence at most latitudes among the experiments varies only by about $20 \mathrm{~W} / \mathrm{m}^{2}$, significantly smaller than corresponding radiative energy convergence which frequently exceeds $60 \mathrm{~W} / \mathrm{m}^{2}$. The latitudinal static energy transports are nearly independent of the surface and of the tropospheric latitudinal temperature gradient. Atmospheric moisture loading and corresponding latent heat transport closely compensate for the reductions in sensible heat transport. In the very coldest experiments, poleward latent heat transports decrease significantly, although sensible heat transports increase somewhat. In these coldest experiments, the global surface temperature is determined essentially by the surface albedo $(0.5)$ that is set for ice covered ocean with input also by snow and clouds.

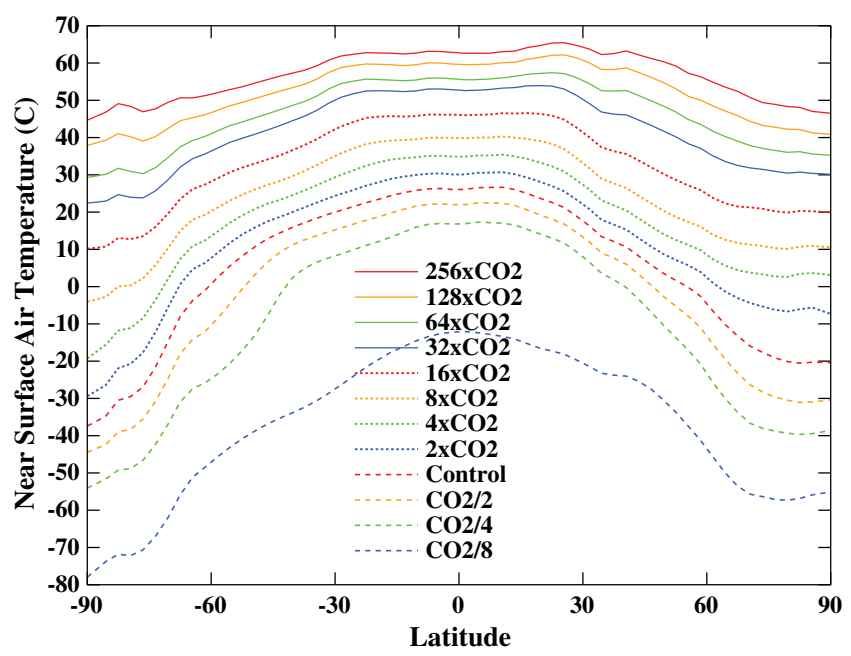

Figure 4. Surface temperature as a function of latitude averaged over the ninth decade of experiment runs. 


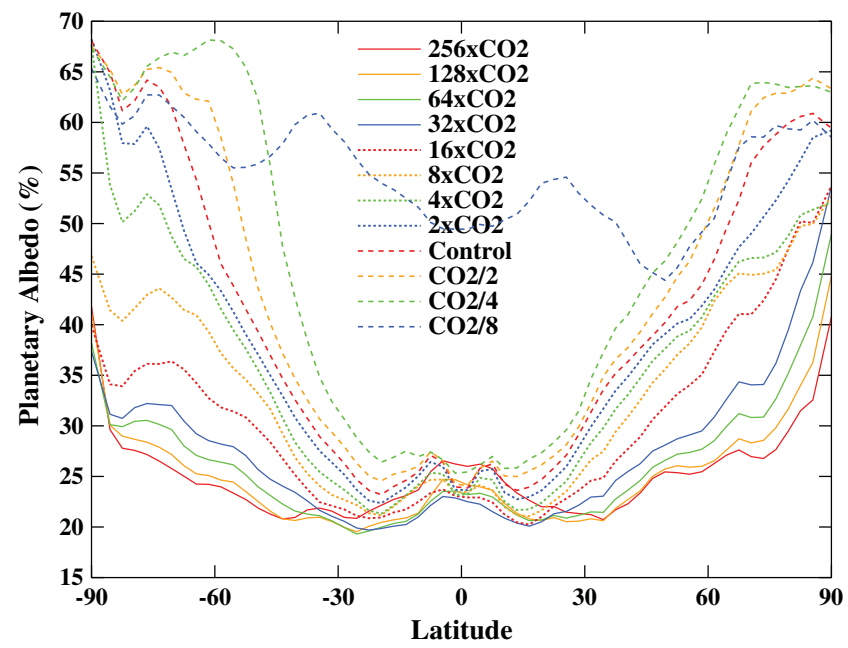

Figure 5. Planetary albedo as a function of latitude averaged over the ninth decade of experiment runs.

[20] Figure 6 shows the global temperature profiles for the ninth decade of each experiment. As $\mathrm{CO}_{2}$ increases, latent heat is transported to greater altitude. Moisture condensation warms the previously cold regions, and the tropopause is obliterated. The advection of moisture to higher altitudes and higher latitudes is associated with an expanded, but weaker, Hadley circulation. Also, there is an increase in the altitude to which convection reaches, although the maximum mass flux remains within the historical troposphere.

[21] More figures from the full set of $\mathrm{CO}_{2}$ experiments that have been cited in the text, but are not shown here, are accessible via the web at http://aom.giss.nasa.gov.

\section{Discussion of Results and Conclusions}

[22] In going from control to $256 \times \mathrm{CO}_{2}$, the water vapor and dry atmospheric mass increase, so too the greenhouse strength by a factor of 2.7. The largest increase occurs for $128 \times \mathrm{CO}_{2}$, where it is $13 \%$ higher than in the control. As the climate warms, cloud cover rises in altitude. The shift to moist convective and ice clouds lowers planetary albedo. With greater warming, this ice cloud feedback effect diminishes, and the planetary albedo changes are smaller. With FAOM, there is no water vapor-induced runaway greenhouse effect due to increased $\mathrm{CO}_{2}$, at least not for the range of $\mathrm{CO}_{2}$ examined. This is consistent with other analyses, including Kasting and Ackerman [1986] who used a one-dimensional radiative-convective model in their analysis.

[23] In contrast to $\mathrm{CO}_{2}$ hot-house experiments, reduced $\mathrm{CO}_{2}$ does lead to runaway sea ice, and to a completely ice covered planet. While water vapor and cloud cover changes are important, the sea ice response overwhelms the other climate feedback processes. Reduced ocean heat transport in the FAOM may allow sea ice to expand with greater facility than would occur with a full ocean model. But this would not alter the basic conclusions that have been reached from the experiments conducted with the faster modeling approach.

[24] When going from $1 / 4 \times \mathrm{CO}_{2}$ to $256 \times \mathrm{CO}_{2}$, the global surface temperature changes by more than $60^{\circ} \mathrm{C}$. For blackbody radiation, the temperatures involved imply a large change in emitted longwave radiation of $374 \mathrm{~W} / \mathrm{m}^{2}$ at the ground surface. However, as shown in Table 2, the outgoing radiation change at the top of the atmosphere was much smaller $\left(44 \mathrm{~W} / \mathrm{m}^{2}\right)$, with a similarly modest change in planetary albedo. The changes in latitudinal energy transports were also relatively small, despite large changes in surface air temperature, the surface latitudinal temperature gradients, atmospheric water vapor, cloud top pressure, and sea ice cover.

[25] One important objective of this modeling analysis has been the need to develop a sufficiently fast climate GCM that is both fast and flexible but is still capable of modeling a wide range of extreme climate situations that might have been encountered in the distant geological past, or that might arise in extreme future perturbations of terrestrial climate, or ones that might have application in evaluating the possibility for habitable climates on the numerous exoplanets that have recently been discovered. But, since climate models in current use typically employ numerous simplifying assumptions and parameterizations specifically designed for current climate applications, and are subject to breaking down when operated beyond their range of tested validity, it is imperative to make the model physics modules more robust.

[26] To meet these objectives, model parameterizations were replaced with more robust physical formulations of the relevant physical and thermodynamic processes. This included making atmospheric composition and dry mass, water vapor, and its impact on the equation of state, as well as the planetary mass and radius into explicit model variables. Treatment of model surface interaction physics was made more robust, precluding spurious oscillations even for ground temperatures in excess of $250^{\circ} \mathrm{C}$. In the condensation routines, supersaturated parcels condense at 99\% relative humidity. Parameterizations were improved to ensure realistic ocean salinities and to conserve water substance in all water reservoirs. The model's radiative calculations were

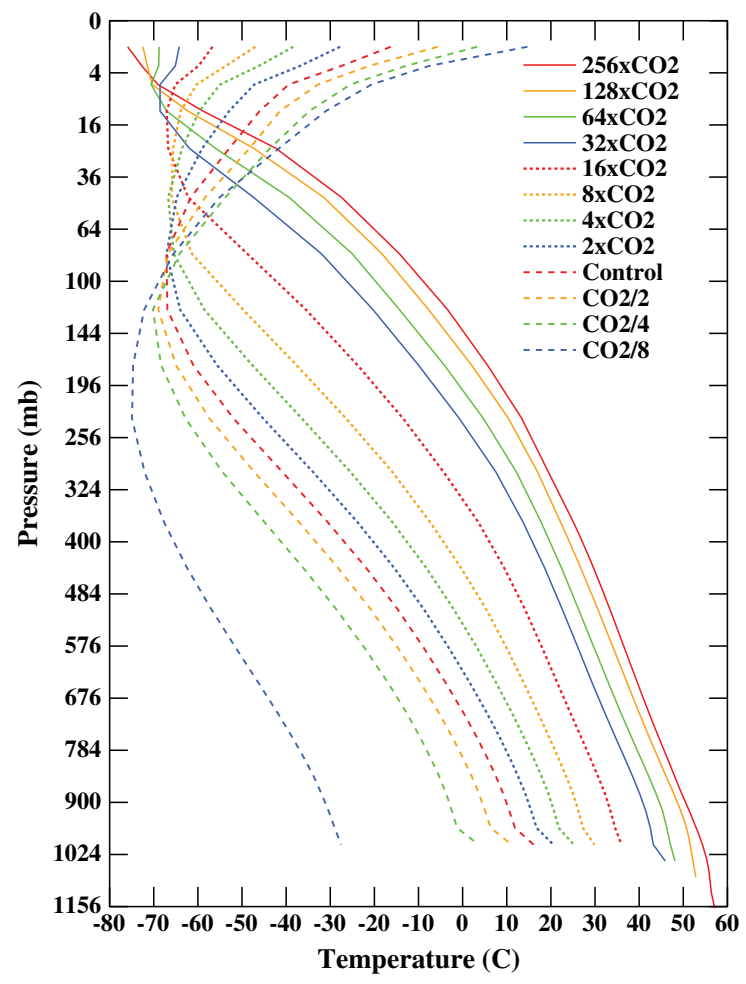

Figure 6. Global mean temperature profiles as a function of pressure computed for the ninth decade of experiment runs. 
spot checked against line-by-line results for extreme temperature and absorber amounts to ensure that the correlated $k$-distribution provides accurate heating and cooling rates under all conditions encountered.

[27] Cloud treatment in the FAOM was kept simplified compared to GISS Model E. Perhaps as a result of this, the attribution analyses in Tables 2 and 3 suggest that the FAOM cloud treatment yields a cloud feedback that is too strongly positive. Coupled with the larger snow-ice feedback due to using the $100 \mathrm{~m}$ ocean, this may account for FAOM climate sensitivity $\left(5^{\circ} \mathrm{C}\right.$ for doubled $\left.\mathrm{CO}_{2}\right)$ being near the high end of the nominal IPCC sensitivity range. While this might affect the absolute value of the climate system response, it would not degrade the basic conclusion that it is changes in atmospheric $\mathrm{CO}_{2}$ that drive global climate from snowball Earth to extreme hot-house conditions. The feedback effects due to water vapor and clouds serve only to establish the actual magnitude of the equilibrium temperature change.

[28] The attribution analyses presented in Tables 2 and 3 describe the SW and LW radiative effects of atmospheric changes in climate system components in response to the extreme changes in radiative forcing. The radiative flux attribution described by Lacis et al. [2010] and Schmidt et al. [2010] provides a basic diagnostic visibility and understanding of how all the different constituents of the climate system change as the climate undergoes extreme variations. The attribution analyses were performed on globally averaged model data based on the ninth decade of each experiment run. Of the averaged model data, the temperature and water vapor profiles were used directly in the radiative modeling, as were the fractions for low, middle, and high cloud cover. The respective cloud optical depths and heights, however, were adjusted to match the FAOM globally averaged SW and LW fluxes (This is because cloud-radiative interactions are too nonlinear for averaged clouds to reproduce averaged radiation.). Note also that the thermal flux to space, $\mathrm{LW}_{E}$ in Table 2, is precisely equal to the absorbed solar flux, $\mathrm{SW}_{a}$ in Table 3. This is because (for clarity in analysis) the $1-2 \mathrm{~W} / \mathrm{m}^{2}$ global energy imbalance due to FAOM nonconversion of kinetic energy into heat is normalized out by uniform adjustment to the temperature profile.

[29] Table 2 describes the fractional contributions of the different atmospheric constituents to the strength of the greenhouse effect. $\mathrm{CO}_{2}$ and the minor greenhouse gases (GHGs) provide the radiative forcing, showing a steady growth as $\mathrm{CO}_{2}$ is increased. The exponential increase in water vapor (as a feedback effect) is by far the greatest contributor to the growing greenhouse strength. The slowly changing cloud LW opacity is a much lesser contributor to the greenhouse strength. Also, to a large degree, the cloud SW (albedo) and LW (greenhouse) effects tend to cancel each other.

[30] Table 3 shows the disposition of the incident solar radiation between the fraction of absorbed $\left(\mathrm{SW}_{a}\right)$ and the fraction reflected to space $\left(\mathrm{SW}_{r}\right)$. Water vapor is the major (atmospheric) absorber of solar radiation, with the bulk absorbed by the ground surface. The reflected radiation is mostly by clouds, with roughly similar amounts by Rayleigh scattering and reflection by the ground surface, except under snowball Earth conditions. This attribution analysis is a useful diagnostic tool that gives quantitative visibility and physical insight to the radiative interactions that take place between different climate system elements as the climate undergoes large structural changes.

[31] Based on our FAOM results, the Earth is presently located at a local minimum in terms of ECS. Moving to large positive or negative changes in $\mathrm{CO}_{2}$ will produce increases in equilibrium sensitivity. We note that burning all available fossil fuel could cause atmospheric $\mathrm{CO}_{2}$ to approach the 4 times the 1950 control run value. This would cause increased drying out and warming of the continental areas, more so than suggested by the global mean temperatures that are plotted in Figure 1. It is clear that such extreme climate conditions would endanger continued human habitation of the Earth.

[32] Acknowledgments. We thank James Hansen for helpful suggestions in regard to the FAOM modeling approach and analysis and Makiko Sato for assistance with graphics display. The NASA Center for Climate Simulations provided computer resources for this paper's calculations. We also express our thanks to NASA Earth Science Research Division, managed by J. Kaye and D. Considine, for support, and we thank the NASA Modeling Analysis and Prediction (MAP) Program for support. We also thank J. Garvin for support for G. Russell and A. Lacis as part of Goddard Space Flight Center's Science Innovation Fund (SIF) Program.

[33] The Editor thanks James Kasting for his assistance in evaluating this manuscript.

\section{References}

Aires, F., and W. Rossow (2003), Inferring instantaneous, multivariate and nonlinear sensitivities for the analysis of feedback purposes in a dynamical system: Lorenz model case study, Q. J. R. Meteorol. Soc., 129, 239-275.

Colman, R., and B. McAvaney (2009), Climate feedbacks under a very broad range of forcing, Geophys. Res. Lett., 36, L01702, doi:10.1029/ 2008GL036268.

Hansen, J., A. Lacis, D. Rind, G. Russell, P. Stone, I. Fung, R. Ruedy, and J. Lerner (1984), Climate sensitivity: Analysis of feedback mechanisms, in Climate Processes and Climate Sensitivity, Geophys. Monogr. Ser., 29, edited by J. E. Hansen and T. Takahashi, pp. 130-163, AGU, Washington, D. C.

Hansen, J., et al. (2005), Efficacy of climate forcings, J. Geophys. Res., 110, D18104, doi:10.1029/2005JD005776.

Intergovernmental Panel on Climate Change (IPCC) AR4 SYR (2007), Climate Change 2007: Synthesis Report, Contribution of Working Groups I, II and III to the Fourth Assessment Report of the Intergovernmental Panel on Climate Change, edited by Core Writing Team, R. K. Pachauri and A. Reisinger, IPCC, Cambridge Univ. Press, Cambridge, United Kingdom and New York, NY, U.S.A.

Jonko, A., K. Shell, B. Snaderson, and G. Danabasoglu (2012), Climate feedbacks in CCSM3 under changing $\mathrm{CO}_{2}$ forcing. Part II: Variation of climate feedbacks and sensitivity with forcing, J. Clim., 26, 2784-2795, doi:10.1175/JCLI-D-12-00479.1.

Kasting, J., and T. P. Ackerman (1986), Climatic consequences of very high carbon dioxide levels in the Earth's early atmosphere, Science, 234, $1383-1385$

Lacis, A. A., G. A. Schmidt, D. Rind, and R. A. Ruedy (2010), Atmospheric $\mathrm{CO}_{2}$ : Principal control knob governing Earth's temperature, Science, 330, 356-359.

Lacis, A., and V. Oinas (1991), A description of the correlated $k$ distribution method for modeling nongrey gaseous absorption, thermal emission, and multiple scattering in vertically inhomogeneous atmospheres, J. Geophys. Res., 96, 9027-9063.

O’Gorman, P. A., R. P. Allan, M. P. Byrne, and M. Previdi (2012), Energetic constraints on precipitation under climate change, Surv. Geophys., 33, 585-608.

Russell, G. L. (2007), Step-mountain technique applied to an atmospheric C-grid model, or how to improve precipitation near mountains, Mon. Weather Rev., 135, 4060-4076.

Russell, G. L., J. R. Miller, and D. Rind (1995), A coupled atmosphere-ocean model for transient climate change studies, Atmos. Ocean., 33, 683-730.

Schmidt, G. A., R. Ruedy, R. L. Miller, and A. A. Lacis (2010), The attribution of the present-day total greenhouse effect, J. Geophys. Res., 115, D20106, doi:10.1029/2010JD014287. 